\title{
LA GRIETA ZAPATISTA EN EL MURO CAPITALISTA: RESISTENCIA Y ORGANIZACIÓN FRENTE A LA HIDRA CAPITALISTA, PENSAMIENTO CRÍTICO Y EDUCACIÓN EMANCIPADORA
}

\author{
THE ZAPATIST CRACKING IN THE CAPITALIST WALL: RESISTANCE AND \\ ORGANIZATION AGAINST CAPITALIST HYDRA, CRITICAL THINKING \\ AND EMANCIPATORY EDUCATION \\ A RACHADURA ZAPATISTA NO MURO CAPITALISTA: RESISTÊNCIA E \\ ORGANIZAÇÃO CONTRA A HIDRA CAPITALISTA, PENSAMENTO CRÍTICO \\ E EDUCAÇÃO EMANCIPADORA
}

Mayra Silva****

maytrova28@yahoo.com

Fernanda Navarro ${ }^{* * * * *}$

fernanda.navarro.sol@gmail.com

\section{REVISTA PEDAGÓGICA}

Revista do Programa de Pós-graduação em Educação da Unochapecó | ISSN 1984-1566

Universidade Comunitária da Região de Chapecó | Chapecó-SC, Brasil Como referenciar este artigo: MEJÍA, N.; GUERREIRO, M. E.; BUEN, A.; SILVA, M.; NAVARRO, F. La grieta zapatista en el muro capitalista: resistencia y organización frente a la hidra capitalista, pensamiento crítico y educación emancipadora. Revista Pedagógica, Chapecó, v. 19, n. 41, p. 18-38, maio./ago. DOI: http://dx.doi.org/10.22196/rp.v19i41.3646

\begin{abstract}
RESUMEN: Este texto es una síntesis de la experiencia zapatista. Uno de sus últimos comunicados: "Que retiemble en sus centros la tierra" nos sorprende de nuevo con su creatividad, audacia y coherencia. Su Mandar Obedeciendo (el pueblo) pronto sorprenderá de nuevo al mundo ante "la agudización del despojo y la represión que no han parado en 524 años en que los poderosos iniciaron una guerra que tiene como fin exterminar a los que de la tierra somos y que como sus hijos no hemos permitido su destrucción y muerte para beneficiar a la ambición capitalista que no conoce fin, más que la destrucción misma”. Aquí presentamos lo que seguimos aprendiendo de las comunidades zapatistas y la fomra como logramos traer su palabra como acción transformadora al aula.
\end{abstract}

Palabras clave: Educación Emancipatoria. Fenda Zapatista. Pensamiento Crítico.

ABSTRACT: The following text "may the earth tremble in its womb". Is a synthesis of one of the latest zapatista experiences which, once again, strikes us, for its daring creativity, and coherence. Its ancestral expression "to order by obeying (the people)" will soon surprise the new world again when devastion and repression - which have not stopped during the past 524 years- since the elite of power started a war with the only purpose to exterminate all of us who belong to mother earth, and as such, with loyalty, have not allowed its destruction and death for the benefit of capitalist ambition". Here, we intend to express what we keep learning from the zapatista communities, as well as the way in which we succeed in using their saying, their true word, in our classroom. Not only for the sake of translation, but in order to turn it into action, an action capable of transforming society.

Keywords: Emancipatory Education. Zapatista Cleft. Critical thinking.

RESUMO: Este artigo é uma síntese da experiência zapatista. Um dos seus últimos comunicados: "Que trema o centro da terra" surpreende-nos novamente com sua 
* Maestría en Pedagogía de la UNAM (Universidad Nacional Autónoma de Mexico).

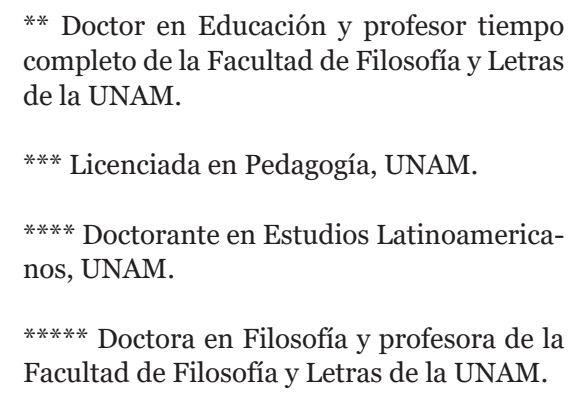
completo de la Facultad de Filosofía y Letras de la UNAM.

*** Licenciada en Pedagogía, UNAM.

**** Doctorante en Estudios Latinoamericanos, UNAM.

***** Doctora en Filosofía y profesora de la Facultad de Filosofía y Letras de la UNAM.

criatividade, ousadia e consistência. Seu Mandar Obedecendo (o povo) logo surpreenderá o mundo novamente para "a intensificação da expropriação e repressão não ter sido interrompido em 524 anos, em que os poderosos iniciaram uma guerra que visa exterminar os que são da terra e como seus filhos não que têm permitido a destruição e morte para beneficiar a ambição capitalista que não tem fim, mais somente a serve a destruição em si”. Aqui está o que seguimos aprendendo com as comunidades zapatistas e a forma como conseguimos trazer a sua palavra à ação transformadora em sala de aula.

Palavras-chave: Educação Emancipadora. Fenda Zapatista. Pensamento Crítico.

\section{INTRODUCCIÓN}

Compañeras y compañeros estudiantes,

Queremos comenzar haciendoles llegar un saludo mexicano y comentarles que al recibir la invitación para participar en la Conferencia "Culturas de resistencia, pueblos e idiomas minorizados" decidimos aceptar este espacio académico sabiendo sus límites pero, al mismo tiempo, teniendo presente que si bien nuestro propio espacio educativo está encerrado por los muros del aula, nos fue posible superarlos gracias a las enseñanzas cotidianas que desde el 1 de enero de 1994 hemos recibido y compartido con las comunidades zapatistas y el EZLN.

Hoy venimos a platicarles algo de ese caminar hermano acompañado por las comunidades zapatistas, formadas por mayas que hablan tzotzil, tzeltal, tojolabal y chol principalmente. Queremos comenzar con una frase en tojolabal que dice: Aj laj ay tik que significa: vamos a emparejarnos, es decir, vamos a buscar las maneras de caminar con las mismas posibilidades pero sobretodo vamos a emparejarnos para vivir con dignidad a pesar de la Hidra capitalista.

Nosotros pensamos que el dolor de la crueldad capitalista seguirá haciendo estragos no sólo en la cultura de los pueblos minoritarios sino en todas y todos los que hoy somos minoritarios y objetos de desecho dentro de su criminalidad. En su proceso de resistencia y organización, las y los zapatistas saben que el capitalismo tiene que ser destruido, no mejorado, ni maquillado.

Aquí, entonces, nuestra palabra que es principalmente un reconocimiento y agradecimiento a las comunidades zapatistas.

Agradecemos la importancia del espacio que se nos ofrece y sabiendo que nuestra propuesta educativa tiene como eje principal la participación estudiantil, decidimos presentar la ponencia en forma epistolar. Nuestros interlocutores son entonces principalmente estudiantes del otro lado del charco pero esperamos de este lado, es decir México, tengamos también interlocutoras e interlocutores.

Tenemos presente que son las y los estudiantes universitarios con quienes hemos logrado hacer una pequeña grieta en el muro del aula, abriendo puertas y ventanas para dejar entrar la frescura y creatividad de la rebeldía zapatista que nos sigue maravillando tanto por 
1 Subcomandante Insurgente Galeano, en El pensamiento crítico frente a la Hidra Capitalista 069, Centro Indígena de Capacitación Integral (CIDECIUNITIERRA) en la ciudad de San Cristóbal de las Casas, México, 5 junio de 2015. Disponible en: <https://www.youtube.com/ watch?v=DMdhypnfHMk $>$. su coherencia como por la fuerza de su palabra, que es lo queremos compartirles.

\section{2 ¿QUIÉNES SOMOS?}

Somos un equipo/colectivo que nos comprometimos a superar los límites del aula, proponiendo una educación donde estudiantes emerjan como sujetos capaces de pensar su práctica para transformarla a favor $-y$ con las y los despojados y excluidos de las riquezas generadas socioeconómicamente, es decir, las grandes mayorías que pueblan y sufren hoy el capitalismo en su etapa neoliberal.

A lo largo de nuestra propuesta educativa, nos ha guiado la construcción de un pensamiento crítico, entendido como palabra y acción transformadora. "Ni teoría sin práctica" - señala el SubGaleano -, ni práctica sin teoría, hemos dicho. No estamos hablando así de la división del trabajo, por allá los que piensan, por acá los que practican. Lo que estamos señalando es que quien hace teoría debe hacer práctica, casi diríamos que por método científico, el pensamiento crítico lleva ese veneno: "si sólo es pensamiento, no llega a ser crítico". "El problema teórico es un problema práctico", aunque se piense que si la realidad no se comporta como la teoría peor para la realidad (EL PENSAMIENTO, 2015, [s. p.]). ${ }^{1}$

Nuestra praxis educativa estudia las consecuencias del capitalismo actual, mercantil, financiero y de guerra, que ha hecho de las culturas, el arte, la educación, la tierra, el aire, el agua, las sociedades y muchas otras cosas más, mercancías para venderse y objetos desechables. Las cuatro ruedas del capitalismo, explotación, despojo, desprecio y represión son las que ruedan siempre como máquina de negocio convirtiendo todo en mercancía. En medio de esa destrucción, superando crueldad y oscuridad, encontramos una luz en el zapatismo, un desafío para organizar resistencias, poner nuestro granito de arena y luchar para destruir ese muro.

Las comunidades zapatistas y el EZLN con su iYa basta! del 1 de enero de 1994, despertaron nuestros sueños y utopías para participar, desde el aula, en la construcción de otro mundo, "una casa nueva, tan grande que en ella quepan no uno sino muchos mundos", como bien apuntan el SubMoisés y el SubGaleano.

No es aquí el espacio para presentarles ni la totalidad de la experiencia de la rebeldía zapatista, ni una síntesis de nuestro proceso educativo. Queremos compartirles solamente las principales experiencias que nos han ofrecido las comunidades zapatistas y el EZLN para hacer una grieta en el muro del aula y convertir el conocimiento y la sabiduría zapatista en acción transformadora. De nuestra propuesta educativa sólo basta decir que ha sido posible dentro de una metodología, práctica y teórica, que construimos reinventando la praxis de Paulo Freire 
2 De Paulo Freire, pueden consultarse sus tres principales Pedagogías: Pedagogía del oprimido; Pedagogía de la esperanza, un encuentro con la Pedagogía del oprimido y; Pedagogía de la autonomía.

3 SubGaleano, en La niña, el muro y la grieta - disponible en: <https://www. youtube.com/watch?v=uptygYuBUiI > . Acceso en: 10 abr. 2017; en El pensamiento crítico frente a la Hidra Capitalista 037disponible en: <https://www.youtube.com/ watch?v=LazwMMff63c $>$. que, a su vez, nació en su trabajo de educación popular. ${ }^{2}$ Trajimos su propuesta a nuestro espacio universitario, la reinventamos, enriquecemos y la llenamos de vida con la praxis zapatista.

Sirva entonces este espacio que ahora compartimos con ustedes, queridas y queridos estudiantes, para preguntarnos sobre ¿qué han hecho y hacen las y los zapatistas para resistir defendiendo suterritorio, comunidad y cultura?, ¿cómo hicieron y mantienen la grieta al muro de la historia?3

Como zapatistas que somos, nuestra memoria también se asoma a lo que viene.

Señala fechas y lugares.

$\mathrm{Si}$ no hay un punto geográfico para ese mañana, empezamos a juntar ramitas, piedritas, jirones de ropa y carne, huesos y barro, e iniciamos la construcción de un islote, o más bien, de una barca plantada en medio del mañana, ahí donde ahora sólo se vislumbra una tormenta.

Y si no hay una hora, un día, una semana, un mes, un año en el calendario conocido, pues empezamos a reunir fracciones de segundos, minutos apenas, y los vamos colando por las grietas que abrimos en el muro de la historia. Y si no hay grieta, bueno, pues a hacerla arañando, mordiendo, pateando, golpeando con manos y cabeza, con el cuerpo entero hasta conseguir hacerle a la historia esa herida que somos.

Y luego pasa que alguien camina cerca y nos ve, ve a la zapatista, el zapatista, duro y dale contra el muro.

Quien así pasa a frente nuestro, es a veces quien cree que sabe. Se detiene un momento, mueve la cabeza con desaprobación, juzga y sentencia: "así nunca van a derribar el muro “...pero a veces... muy de cuando en cuando... [pasa quien se mira y elige...].

La teoría zapatista nacida de su resistencia, como nos lo explican en sus escritos, es colectiva y hace parte delpensar su acción, construyendo un pensamiento crítico transformador. Suspalabras, con la que caminan el mundo preguntando, son semillas que nos proponen para sembrar nuestros propios pensamientos, aprendiendo a preguntar para mejor poder caminar. Aprender a pensar el pensamiento y preguntarnos como lo hacen las/os zapatistas por ejemplo, ¿por qué esto y no otra cosa? ¿Por qué así y no de otro modo? ¿Por qué aquí y no en otro lugar?

A continuación entonces, algunos pasos que desde nuestra mirada han hecho posible otro modo de vida: el caminar autónomo de las y los zapatistas.

\section{LEER EL MUNDO PARA PRONUNCIARLO}

Leer el mundo, desde lo cotidiano parece obvio, sin embargo es una actividad que al no poder realizarse de 
manera directa se complica mucho - no es tan obvio -, pues nuestra percepción es siempre mediada perversamente y no es fácil informarnos para saber lo que sucede, principalmente con los movimientos sociales. Nuestra capacidad de lectura debe agudizarse, pues el mal gobierno sabe usar los medios de paga - lo que no es peyorativo como afirma el SubGaleano sino que se sabe que son medios que funcionan gracias al dinero que reciben, o sea, que son de paga - a su favor para trampear la realidad, deformarla, anestesiarla, para decir verdades a medias, escondiendo lo que realmente sucede: en la actualidad se paga para no difundir la verdad de lo que sucede. Las y los zapatistas saben bien de ello y han asumido el compromiso de leer el mundo desde una mirada crítica y pronunciarse, es decir, compartir lo que viven y vivimos ante el actual capitalismo, una Hidra criminal que devora todo a su paso. El proceso de construcción del pensamiento crítico zapatista ha sido explícito en sus seis Declaraciones de la Selva Lacandona:

PRIMERA DECLARACIÓN, 1993. Hoy decimos: iBasta! Somos producto de 500 años de lucha. Nosotros, hombres y mujeres íntegros y libres, estamos conscientes de que la guerra que declaramos es una medida última pero justa.

SEGUNDA DECLARACIÓN, JUNIO 1994. Hoy decimos: iNo nos rendimos!Los poderes de la Unión ignoraron nuestras justas demandas y permitieron la masacre. Pero sólo duro 12 días esta pesadilla, pues otra fuerza superior a cualquier poder político o militar se impuso a las partes en conflicto. La Sociedad Civil asumió el deber.

Sabremos esperar... y sabremos volver si se cierran de nuevo todas las puertas para que la dignidad camine.

TERCERA DECLARACIÓN, ENERO 1995. iLa patria vive! iY es nuestra! Hoy, después de haber llamado primero a las armas y posteriormente a la lucha civil pacífica, llamamos a la formación de un movimiento para la liberación nacional.

CUARTA DECLARACIÓN, ENERO 1996. Hoy decimos: iAquí estamos! iSomos la dignidad rebelde, el corazón olvidado de la patria!

QUINTA DECLARACIÓN, JULIO 1998. Hoy decimos: iAquí estamos! iResistimos! Contra la guerra, no otra guerra sino la misma resistencia digna y silenciosa.

SEXTA DECLARACIÓN, JUNIO 2005. Llamar a quienes son como nosotros. Analizando sobre Lo que somos; De dónde estamos ahora; De cómo vemos el mundo; De cómo vemos a nuestro país; De lo que queremos hacer; y De cómo lo vamos hacer... Es preguntarles cómo es su vida, su lucha, su pensamiento, de cómo está nuestro país y cómo hacemos para que no nos derroten. ${ }^{4}$ 
5 Subcomandante Insurgente Marcos, en Entre la luz y la sombra. La Realidad, planète Terre. Mayo del 2014. Disponible en: <https://www.youtube.com/ watch?v=ZuV4eS2S4RI $>$.
6 Tratado de libre comercio de América del Norte, en: <https://es.wikipedia.org/ wiki/Tratado_de_Libre_Comercio_de_ Am\%C3\%A9rica_del_Norte>.

7 Subcomandante Insurgente Marcos (ENTRE LA LUZ, 2014).
Desdela "Primera Declaración dela Selva Lacandona", 1994, hasta la más reciente, La Sexta, 2005, el EZLN ha logrado convocar periódicamente tanto al Congreso Nacional Indígena, CNI, como a los pueblos de México y del mundo; juntar rebeldías y resistencias para destruir ese monstruo real, y no mitológico, en que se convirtió el capitalismo, la Hidra Capitalista como hoy el zapatismo lo nombra. Para luchar contra ese monstruo real y no caer en su juego criminal, de ser soldados para la muerte, los pueblos zapatistas se convirtieron en centinelas de la vida. ${ }^{5}$

Yen lugar de dedicarnos a formar guerrilleros, soldados y escuadrones, preparamos promotores de educación, de salud, y se fueron levantando las bases de la autonomía que hoy maravilla al mundo [...]. En lugar de construir cuarteles, mejorar nuestro armamento, levantar muros y trincheras, se levantaron escuelas, se construyeron hospitales y centros de salud, mejoramos nuestras condiciones de vida [...]. Y el más importante: el relevo de pensamiento: del vanguardismo revolucionario al mandar obedeciendo; de la toma del Poder de Arriba a la creación del poder de abajo; de la política profesional a la política cotidiana; de los líderes, a los pueblos; de la marginación de género, a la participación directa de las mujeres; de la burla a lo otro, a la celebración de la diferencia. (ENTRE LA LUZ, 2014, [s. p.]).

\section{NOMBRAR Y ENFRENTAR LA HIDRA CAPITALISTA}

De ese sótano, supuestamente sin cultura, sin historia, una nueva casa venía construyéndose y hacia grietas a la Hidra Capitalista. Una casa que decidieron construir arañando el muro de la historia, aprendiendo a tejer su memoria histórica sabiendo que el mal gobierno mexicano les había cerrado todas las puertas. El Tratado de Libre Comercio de América del Norte (TLCAN), 1991, sellaba la opresión, desprecio y despojo de los pueblos zapatistas, simplemente se decretaba que ya no tenían ninguna forma de existencia. ${ }^{6}$ Por ello, se vistieron de guerra para hacerse visibles con mujeres y hombres decididas/os a matar para vivir.

Pero, a 12 días de haber comenzado la guerra contra el mal gobierno - o sea, el 12 de enero de 1994 - la sociedad mexicana hizo suyas las demandas zapatistas y obligó a la negociación. Una negociación que, como era de esperar, fue traicionada por el Gobierno Mexicano una vez firmados los acuerdos, llamados de San Andrés, entre las dos partes, 1996. Las comunidades zapatistas siguieron su lucha de organización de la resistencia, en ocasiones en silencio, otras denunciando las atrocidades de la Hidra en su cabeza mexicana y mundial: ${ }^{7}$ 
8 SubMarcos, su despedida y nacimiento del SubGaleano (ENTRE LA LUZ, 2014).

9 Actualmente se está en el segundo nivel de la Escuelita Zapatista. El primero tuvo lugar en 2013 y el segundo en 2015.

10 Conferencia de prensa Sub Galeano a medios libres, La Realidad, México, 9 de agosto de 2014. Disponible en: <https://www.youtube.com/watch?v=tS VH870UMb4>.
Nada de lo que hemos hecho, para bien o para mal, hubiera sido posible si un ejército armado, el zapatista de liberación nacional, no se hubiera alzado contra el mal gobierno ejerciendo el derecho a la violencia legítima. La violencia del de abajo frente a la violencia del de arriba.

[...] Lo que para nosotros inicia en 1994 es uno de los muchos momentos de la guerra de los de abajo contra los de arriba, contra su mundo. Esa guerra de resistencia que día a día se bate en las calles de cualquier rincón de los cinco continentes, en sus campos y en sus montañas. Era y es la nuestra, como la de muchos y muchas de abajo, una guerra por la humanidad y contra el neoliberalismo.

La lucha indígena - pueblos de cultura maya mayoritariamente - supo resistir a la invasión colonial española de ayer, y hoy desafía la crueldad neocolonial capitalista. En un primer momento la cabeza visible del EZLN fue su vocero, el Subcomandante Insurgente Marcos, personaje identificado como el "líder" por los medios de desinformación. El EZLN jugó con esa falsa designación, utilizando al $S u b$ como distractor hasta el 2014 mientras se consolidaba en sus comunidades la organización de su resistencia (ENTRE LA LUZ, 2014). ${ }^{8}$ Así, se daba origen a esa propuesta que hoy maravilla a quienes hemos tenido la oportunidad de compartirla en distintos espacios o en sus mismas comunidades, en especial con la participación al Primer nivel de la escuelita, "La libertad según los zapatistas", 2013. ${ }^{9}$

El SubMarcos fue entonces una realidad virtual. Con el excelente manejo de los medios de comunicación que ha caracterizado al zapatismo, lograron con ese personaje desviar la atención de lo que estaba ocurriendo en sus comunidades. El manejo de lo virtual, de la nueva cultura de la imagen fue otra gran enseñanza para saber cómo combatir esos medios de paga al servicio del gran capital. Pero, esos medios no bajaron los brazos y han intentado distorsionar, anestesiar y bloquear la percepción de la realidad para impedir conocer lo que realmente sucede. La respuesta zapatista fue la de excluir a esos medios y sólo abrir la puerta a los medios libres, alternativos, autónomos o como se llamen. ${ }^{10}$

En este contexto, para el 2014 (a la edad de 20 años), las comunidades zapatistas y el SubMarcos decidieron desaparecer la figura del Subcomandante Insurgente Marcos, (dejarlo como botarga para la realidad virtual) y confrontar a la sociedad con la realidad vivida de traición y guerra. Esto debido al asesinato de un zapatista, el maestro Galeano, de quien el $S u b$ toma su nuevo nombre llamándose ahora, Subcomandante Insurgente Galeano dejando de ser el vocero del EZLN y cediendo este cargo al Subcomandante Insurgente Moisés para mostrar que esencialmente la dirección indígena está a cargo de ellos y ellas. 
11 Subcomandante Insurgente Marcos (ENTRE LA LUZ, 2014).
12 Subcomandante Insurgente Marcos, en Cuáles son las características fundamentales de la IV Guerra Mundial?. Disponible en: <http://enlacezapatista. ezln.org.mx/2003/02/01/cuales-son-lascaracteristicas-fundamentales-de-la-ivguerra-mundial $>$.
El nuevo vocero del EZLN es entonces el SubMoisés con quien ahora camina el SubGaleano, juntos van reivindicando resistencias y esperanzas de lucha como es señalado en la primera aparición pública del SubGaleano (ENTRE LA LUZ, 2014, [s. p.]): ${ }^{11}$

El culto al individualismo encuentra en el culto al vanguardismo su extremo más fanático. Y ha sido eso precisamente, el que los indígenas manden y que ahora un indígena sea el vocero y jefe, lo que los aterra, los aleja, y finalmente se van para seguir buscando alguien que precise de vanguardias, caudillos y líderes. Porque también hay racismo en la izquierda, sobre todo en la que se pretende revolucionaria.

Desde la ociosa reflexión de Descartes, la teoría de arriba insiste en la primacía de la idea sobre la materia. El "pienso, luego existo" definía también un centro, el YO individual, y a lo otro como una periferia que se veía afectada o no por la percepción de ese $Y O$ : afecto, odio, miedo, simpatía, atracción, repulsión. Lo que estaba fuera del alcance de la percepción del $Y O$ era, es, inexistente.

Así, el nacimiento de este crimen mundial llamado capitalismo es producto de la máquina de vapor y no del despojo. Y la etapa capitalista de la globalización neoliberal arranca con la aparición de la informática, el internet, el teléfono celular, el mall, la sopa instantánea, el fast food; y no con el inicio de una nueva guerra de conquista en todo el planeta, la IV Guerra Mundial. (ENLACE ZAPATISTA, 2003a, [s. p.]). ${ }^{12}$

En el campo de la tecnología se repite el mismo patrón. Y se agrega que, como el concepto científico, la técnica nace "inocente", "libre de toda culpa", "inspirada en el bien de la humanidad". Einstein no es responsable de la bomba atómica, ni el señor Graham Bell lo es de los fraudes vía celular del hombre más rico del mundo, Carlos Slim. El coronel Sanders no es responsable de las indigestiones provocadas por el Kentucky Fried Chiken, ni el señor MacDonald de las hamburguesas de plástico reciclado".

Entonces, la eliminación de la figura del SubMarcos es otro acto de congruencia, se busca resaltar que las comunidades se organizan más allá de las figuras individuales, reconociendo que la democracia sólo existe si todas las voces se escuchan y emerjen en la construcción de una individualidad nacida del colectivo y no aquella que se queda en el individualismo; teniendo claro que la rabia debe organizarse en Digna Rabia. 
13 Subcomandante Marcos, en: Palabras por el nacimiento de las Juntas de Buen Gobierno. <http://enlacezapatista.ezln.org. $\mathrm{mx} / 2003 / 08 / 09 /$ subcomandante-marcospalabras-por-el-nacimiento-de-las-juntasde-buen-gobierno>.

\section{DE LA DIGNA RABIA A ORGANIZAR LA RESISTENCIA}

Compañeras y compañeros estudiantes, el dolor, el olvido y la rabia en donde estaban siendo aplazatados(as) cotidianamente las comunidades zapatistas por las cuatro ruedas del capitalismo - "explotación, despojo, desprecio y represión" - se convirtió en Digna Rabia. Esta nació siendo colectiva como propuesta de lucha, de resistencia y de organización. Es amorosa y creativa, no es destructiva: la no eliminación del hermano(a) marca sus pasos. Junta la fuerza de la rabia, del coraje y de la indignación para aprender enseñando a tejer otra historia donde se respete la vida, al hermano(a) y a la madre tierra, sabiendo que ella nos nutre: vivir y morir es fecundarla. La cosmovisión zapatista hace suya la de la mayorías de los pueblos originarios, siendo al mismo tiempo cosmovisión y cosmovivencia que nos hermana con todo lo que vive: todo tiene corazón. Ese corazón nos permite sentir, pensar y caminar siendo guia de acción.

Esta cosmovisión y cosmovivencia es totalmente diferente a la occidental centrada en el antropocentrismo. Para los mayas, por el contrario, se trata de un Biocentrismo.

Este pronunciamiento colectivo en defensa de la vida es resultado de la organización de las comunidades zapatistas quienes decidieron dar nacimiento a sus Caracoles en donde, a su vez, nacen las Juntas de Buen Gobierno (2003) y se Manda obedeciendo. El caracol es el que sirve para llamar al pueblo a sus asambleas para resolver los problemas que les atañen. La finalidad principal de sus Caracoles es la consolidación de sus autonomías. Su iYa basta! guerrero les permitió conquistar y recuperar su territorio $\mathrm{y}$, al hacerlo suyo lo defienden (ENLACE ZAPATISTA, 2003b, [s. p.]). ${ }^{13}$

Sus primeros pasos cuando nació la guerra contra el olvido, en la negociación con el mal gobierno, fue de "pedir". Pero, ante los oídos sordos y la guerra que continuaba y continúa pasaron a "exigir" y finalmente, gracias a todos estos años de silencio y organización de su resistencia, han logrado "ejercer" la Autonomía sobre sus territorios, para así empezar a construir un mundo donde quepan muchos mundos, sin perder de vista su desafío principal: destruir la Hidra Capitalista, siempre sabiendo que la liberación debe ir más allá de sus territorios.

Aunque el zapatismo parte del supuesto de que el sistema capitalista es el dominante, le acompaña la certeza de que no es omnipresente, ni inmortal; enfrentan resistencias de arriba aunque las de abajo son las que lo amenazan. Pero, mientras la Hidra tenga el terreno libre podrá seguir reconstruyendo sus cabezas - esas que comanda la corrupción en todos sus dominios - no habrá posibilidad alguna de vida digna, de una nueva casa mundo. Sin embargo, el zapatismo no se rinde y más que vencer, intenta convencer acerca de la importancia de la 
14. En: El pensamiento crítico frente a la Hidra Capitalista I.
15 Subcomandante Insurgente Moisés, en: El pensamiento crítico frente a la Hidra Capitalista 037. Disponible en: $\quad<$ https://www.youtube.com/ watch?v=LazwMMff63c $>$. Centro Indígena de Capacitación Integral (CIDECIUNITIERRA) en la ciudad de San Cristóbal de las Casas, México, 25 de mayo de 2015.
Dirección Colectiva, compartiendo su experiencia que se niegan a definirla como revolucionaria para impedir interpretaciones que están lejos de entender su rebeldía. ${ }^{14}$

La pérdida de legitimidad de las instituciones "tradicionales" (partidos, gobierno, sistema judicial, iglesia, ejército, policía, medios de comunicación, familia) y el nulo intento de recuperarla [...] La corrupción tan escandalosa en las clases políticas que raya en la psicopatía. Es tal el nivel de degradación que el verdadero Poder, el del dinero, está escandalizado. Tanto que temen que lo que no hizo la arbitraria tiranía del dinero, lo haga la corrupción en los gobernantes: porvocar una rebelión [...] Estamos frente a una realidad que se sintetiza hoy en una sola palabra: Ayotzinapa. Para nosotras, nosotros, zapatistas, Ayotzinapa no es la la excepción sino la regla actual. Ahi está el retrato de familia a nivel mundial. (EZLN, [s. d.], p. 215-216).

\section{LA DIRECCIÓN COLECTIVA}

El largo camino zapatista de aprender a "escuchar" al otro(a) se enlaza con el Mandar Obedeciendo cuyo origen está fundado en las culturas mayas milenarias que son eje de su lucha de resistencia y organización. "escuchar" para los pueblos mayas originarios no es sinónimo de "oír". No sólo implica ponerse en el lugar del otro(a) para comprenderlo, sino ponerse en la piel del otro(a), del hermano(a), juntar corazones: la escucha "hermana". Y, además, entre hermanos(as) no puede haber enemigos, no se equivocan de enemigo. Lo anterior se vincula con el TIK que significa "nosotros", corazón de sus Asambleas, que son su máxima autoridad. En ellas se dialoga, como hoy lo entienden, se llega a una "compartición" para buscar un consenso colectivo, nunca uni-personal. Este proceso es el que consolida las Juntas de Buen Gobierno Zapatistas donde se eligen y participan sus autoridades, elegidas democráticamente cumpliendo los principios de las tres R: "Rotatividad, Revocabilidad y Rendición de cuentas".

La encarnación de la Dirección Colectiva la podemos apreciar, escuchar, entender en la sabiduría del SubMoisés, sus palabras retoman siempre el sentir y pensar colectivo, su corazón que se hace palabra de organización para la acción. Pero, claro, él hace parte de esa memoria milenaria del sabio en las comunidades indígenas, su voz es la voz de los sin voz, corazón de la tierra, luz y sombra en el camino. Por ello, el anciano y la Comandancia Zapatista -Comité Clandestino Revolucionario Indígena - Comandancia General del EZLN - es quien manda obedeciendo a sus comunidades, lo que ha sido y es indispensable para entender la rebeldía zapatista. ${ }^{15}$ 
16 Comandanta Miriam, Centro Indígena de Capacitación Integral (CIDECIUNITIERRA) en la ciudad de San Cristóbal de las Casas, México México, 6 de mayo de 2015. Disponible en: <http:// enlacezapatista.ezln.org.mx/2015/05/o6/ comandanta-miriam-6-de-mayo $>$.
17 Compañera escucha Selene, Centro Indígena de Capacitación Integral (CIDECIUNITIERRA) en la ciudad de San Cristóbal de las Casas, México 6 de mayo de 2015. Disponible en: <http://enlacezapatista.ezln. org.mx/2015/05/o6/companera-escuchaselena-6-de-mayo $>$.
Las Juntas de Buen Gobierno hacen posible una Dirección Colectiva para responder, desde abajo y a la izquierda, a las necesidades concretas de su vida cotidiana. En asambleas se identifican problemas que en colectivo es necesario estudiar y resolver, sin perder de vista que la guerra contra sus comunidades es permanente. Pero también lo es, el sentido de vida y creatividad comunitario de los pueblos que saben tejer su resistencia, ir permanentemente a una organización más horizontal. Así nació en sus comunidades Otra salud, Otra educación, Otra agricultura, Otra economía, Otra organización política radicalmente diferente a la impuesta por el modelo de la globalización capitalista, por la crueldad de la Hidra Capitalista.

Pero también, así renació, se hizo presente y rompió el silencio la mujer indígena. Su voz como dadora de vida, como única capaz de sentir la gestación del ser humano, se hizo flor rebelde participando en la lucha contra las estructuras phalocráticas, patriarcales, machistas y misógenas que han decidido el rumbo de la historia de toda la humanidad, ya sea sobre el cuerpo de la mujer, sobre la madre tierra, destruyendo e imponiendo esas ruedas capitalistas con las que se ha querido aplastar su cosmovisión y cosmovivencia. La mujer como dadora de vida se hizo defensa de la vida. La Comandanta Miriam nos recuerda: ${ }^{16}$

Desde la llegada de los conquistadores, sufrimos la triste situación de las mujeres. Nos despojaron nuestras tierras, nos quitaron nuestra lengua, nuestra cultura. Es así donde entró la dominación del caciquismo, terratenientes, entra la triple explotación (patrón, esposo, hijos), humillación, discriminación, marginación, maltrato, desigualdad. (ENLACE ZAPATISTA, 2015a, [s.p.]).

Con la organización de su lucha las comunidades zapatistas, estando dispuestas y dispuestos a matar para vivir, lograron recuperar sus territorios, apropiarse de ellos, crear nuevas relaciones de producción reconstruyendo tejidos sociales orientados por sus 13 demandas zapatistas: "tierra, cultura, educación, pan, democracia, trabajo, paz, techo, salud, independencia, libertad, información y justicia”. Con ellas han logrado que las nuevas generaciones también vayan siendo parte del proyecto como explica Selena: ${ }^{17}$

Nosotras como zapatistas, somos pobres pero ricos de pensar, ¿̇por qué? Porque aunque ponemos los zapatos y la ropa, los celulares, no cambiamos nuestra idea ni nuestra costumbre de vivir, porque a nosotros como jóvenes zapatistas no nos importa cómo estemos vestidos, o cómo sean nuestras cosas 
18 Comandanta Concepción En Los Pueblos Zapatistas y la Otra Educación I, Disponible en: <https://www.youtube.com/ watch?v=FfQkwxODO44>. que usamos, lo importante es que los trabajos que hacemos es para el bien del pueblo, que es lo que queremos nosotros como zapatistas; que es lo quiere en todo el mundo, que no haya mandones, que no haya explotadores, que no estemos explotados como indígenas. (ENLACE ZAPATISTA, 2015b, [s. p.]).

\section{LA OTRA EDUCACIÓN}

"La Otra educación es nuestra" dice la Comandanta Concepción moderadora del encuentrojuntoal Comandante Abel, "porque es nuestra la educación que nosotras hemos venido practicando y haciendo en todo nuestro territorio". "[...] La educación del mal gobierno no iba de acuerdo al medio indígena, obligaban aprender de acuerdo a lo que les daba la gana. Pero, a través de la organización, “[...] comenzaron a resistir por muchos años, aprendieron a resistir y a ver la forma de hacer su propia educación. Se nombraron y formaron promotores para que los niños comenzaran a estudiar." "Nuestra lucha", continúa la Comandanta Concepción, "[...] nos ha sacado adelante y hemos aprendiendo en todos los niveles y es por eso que nosotros como zapatistas ahora vamos caminando con nuestra educación". Conforme Concepción "[...] Aunque el mal gobierno buscaba como acabarnos: imponiendo trabas, todas sus trampas para mandarnos a vigilar". ${ }^{18}$

La milenaria lucha de resistencia de las comunidades zapatistas en 1994 les llevó a decidir la guerra contra el mal gobierno y si bien sus pasos fueron guerreros, pronto - a doce días de comenzada la guerra contra el mal gobierno del fuego nació la palabra digna, llamando a la organización de resistencias en todo el planeta. Su memoria es un presente que se proyecta al futuro.

Compas estudiantes, en este escrito hemos querido hacer énfasis más que en la definición de conceptos, en su epistemología, o sea, el proceso de creación de conocimientos. Nuestra propuesta educativa, política e ideológica, al lado de los(as) zapatistas ha transformado nuestra "lectura de la realidad en el aula".

Nosotras, nosotros decidimos caminar "escuchando" y preguntando para seguir agrietando el muro. Pero ustedes saben bien que no es fácil comenzar a arañar el muro. No lo es porque ese muro del aula hace parte de ese otro muro/conocimiento que se difunde en el aula, utilizado sólo para la trasmisión de saberes, en muchas ocasiones con actitudes autoritarias y dogmáticas. Y, sin importar qué tipo de conocimiento se transmite - ya sea de derecha, izquierda o el mal llamado de centro - parece que ha servido solamente para alimentar la voracidad de la Hidra, para estampar a estudiantes al muro como otra figura de la decoración en el aula.

Tercamente nosotras, nosotros, decidimos que podíamos agrietar ese muro, eso sí, sabiendo que no 
19 Subcomandante Insurgente Moisés y Subcomandante Insurgente Galeano en: Una casa, otros mundos (ENLACE ZAPATISTA, 2016a). estábamos solas, solos, pues nos acompaña ese iYa basta! guerrero que rompió el silencio denunciando injusticias, despojos, discriminaciones y explotaciones. Las y los indígenas estaban en el sótano de la historia, se utilizaba - y se sigue considerando - su cultura como folklor, artesanía y ritual para divertir y entretener. $\mathrm{Al}$ respecto nos comparten y cuestionan: ${ }^{19}$

[...] como somos pueblos originarios, un@s y otr@s piensan que lo que hacen ell@s es arte y cultura, y lo que hacemos nosotros es artesanía y ritual, que lo que en ell@s es análisis y conocimiento, en nosotros es creencia y superstición. Ignoran que nosotros pintamos colores que, cientos de años después, aún desafían los calendarios, que cuando en la "civilización" todavía creían que la tierra era el centro y ombligo del universo, nosotros ya habíamos descubierto astros y números. Creen que amamos la ignorancia, que nuestro pensamiento es simple y conformista, que preferimos creer en lugar de conocer. Que nosotros no queremos el avance, sino el retroceso [...] ¿QQué se necesita para construir una casa nueva, tan grande que en ella quepan no uno sino muchos mundos?. (ENLACE ZAPATISTA, 2016a, [s. p.]).

Finalmente compas estudiantes, si nos permiten esta hermosa expresión zapatista, queremos tener en la mente y el corazón dos preguntas centrales: ¿qué hemos aprendido trayendo la vivencia zapatista al muro del aula? La otra: y ¿tú qué?

En nuestro espacio educativo, con las diferencias radicales entre aula y comunidades zapatistas, aprendimos a construir una dirección colectiva sabiendo que las contradicciones y conflictos vividos en la relación entre Autoridad del profesor(a)yla Libertad delasylos estudiantes son un freno a dicha dirección. En el aula, por ejemplo, el primer desafió que hemos enfrentado es la relación entre la herencia autoritaria y discursiva de docentes y la historia educativa de estudiantes, estos últimos tratados como objetos de depósito de los conocimientos que se transmiten en el aula, tienen que aprender a escuchar pero no en el sentido zapatista sino como actitud ante una narración, el discurso abstracto y sin contexto social. Nosotras y nosotros proponemos a estudiantes un proceso de "emancipación" aprendiendo y enseñando con ellas/ellos a leer su práctica educativa y política para transformarla.

Combinando las enseñanzas zapatistas y la experiencia freiriana en el aula, creemos que esta relación entre autoridad y libertad se vive de manera muy similar en toda la sociedad globalizada, pues la Autoridad Autoritaria que una vez en el poder manda mandando, convierte a la sociedad en objeto de depósito de "información" a través de los medios al servicio del poder-dinero, que se encargan 
20 En Resistencia y Rebeldía I, Disponible en: $\quad$ <http://www.grieta.org.mx/index. $\mathrm{php} / 2015 / 05 / 06 /$ resistencia-y-rebeldiai-subcomandante-insurgente-moises $>$. En la página de Grieta, Medio para armar, se puede consultar todo lo referente al EZLN (esta página <http://www.grieta.org.mx> se encuentra entrando a la página zapatista: $<$ http://enlacezapatista.ezln.org.mx>. de difundir versiones tergiversadas de lo que en realidad se vive en el mundo con la intención de confundir, anestesiar e impedir que la sociedad salga en defensa de la vida, del hermano(a), de la madre tierra.

No obstante, las redes sociales alternativas de comunicación son grieta también que posibilitan la lectura de nuestro entorno y con ello procesos de enancipación, donde surgen nuevos retos: romper el silencio y pronunciarnos, organizarse, transformar el mundo transformándonos a nosotras/os mismos(as), asumir la libertad con la responsabilidad que implica y exige. Retos que las comunidades zapatistas nos muestran que se pueden realizar, pero que no es cosa sencilla, se trata de aprender a resistir, como lo señala el Subcomandante Insurgente Moisés (2015, [s. p.]), las embestidas permanentes de la Hidra Capitalista. ${ }^{20}$

Ya ahorita ya podemos dar varios sentidos lo que es rebeldía y resistencia para nosotros, porque es que ya fuimos descubriendo, practicando en los hechos, o sea ya podemos dar, como se dice, teoría, pues. Para nosotros la resistencia es ponerse fuerte, duro, para dar respuesta a todo, cualquiera de los ataques del enemigo, del sistema pues; y rebelde es ser bravos, bravas para igual responder o para hacer las acciones, según la que convenga, entonces hay que ser bravas y bravos para hacer las acciones o lo que necesitamos hacer [...] Entonces la resistencia descubrimos de que no es nada más resistir a tu enemigo, de no recibir lo que da, las limosnas o los sobrantes [...] Entonces es no tenerle miedo, hay que tener resistencia, o sea tienes que ponerte fuerte de que no corras cuando escuchas el ruido [...] Pero lo que hemos visto es que la resistencia, sabiéndola organizarla y teniendo organización primero por supuesto, porque no puede haber así nada más resistencia y rebeldía si no hay organización, entonces organizar esas dos armas de lucha podemos decir así -, nos ayudó mucho para tener, digamos que se abre más la mente, la forma de ver.

Regresando al aula, es necesario tener claridad en que la mayoría de estudiantes no están interesados en un proceso de concientización como el que se propone. Menos aún cuando estando en la universidad ya hacen parte de los "elegidos" por el sistema educativo de exclusión, listos para aprender a eliminar - sin sentimiento de culpa alguno - al otro(a) y, no existe un interés más allá de la calificación. Sin embargo, no son pocos los y las estudiantes que se comprometen en un trabajo directo con los(as) explotados(as). Por ejemplo, quienes escribimos esta ponencia, en su mayoría, somos ex estudiantes que hemos seguido las asignaturas de Miguel Escobar y hemos participado directamente en distintas invitaciones 
21 En el caminar construyendo la lucha, el SubMarcos, no compartió antes de dejar de existir, la lucha zapatista a través de varios personajes por él creados: don Durito, el viejo Antonio, Elias Contreras y la Magdalena, Sombra, el guerrero (en la página zapatista puden encontrarse referencias a estos personajes de quienes también hay libros dedicados a cada uno). En: Los zapatistas $y$ las manzanas (SUBCOMANDANTE INSURGENTE MARCOS, 2002. Disponible en: <http://palabra.ezln.org.mx/ comunicados/2002/2002_11.htm>. y propuestas zapatistas. Pero también contamos con la presencia y apoyo de Fernanda Navarro que además de ser profesora de nuestra Facultad está en contacto directo y permanente con las comunidades zapatistas.

Muchas palabras y preguntas zapatistas caminan al paso de cuentos y fábulas. Por ello, veamos lo que hemos aprendido de uno de los extintos personajes creados por el difunto SubMarcos, don Durito, un simpático escarabajo que vive en las montañas del sureste chiapaneco, quien reflexiona sobre la vida y la forma en que las y los zapatistas la conciben: ${ }^{21}$

Dice Durito que la vida es como una manzana. $\mathrm{Y}$ dice también que hay quienes la comen verde, quienes la comen podrida y quienes la comen madura.

Dice Durito que hay algunos, muy pocos, quienes pueden elegir cómo se comen la manzana: si en un hermoso arreglo frutal, en puré, en uno de esos odiosos (para Durito) refrescos de manzana, en jugo, en pastel, en galletas, o en lo que dicte la gastronomía.

Dice que los pueblos indios se ven obligados a comer la manzana podrida y que a los jóvenes les imponen la digestión de la manzana verde, que a los niños les prometen una hermosa manzana mientras se las envenenan con los gusanos de la mentira, y a las mujeres les dicen que les dan una manzana y sólo les dan media naranja.

Dice Durito que la vida es como una manzana. Y dice también que un zapatista, cuando está frente a una manzana, le saca filo a la madrugada y parte la manzana, con certero golpe, por la mitad.

Dice Durito que el zapatista no intenta comerse la manzana, que ni siquiera se fija si la manzana está madura, o podrida, o verde. [...] Abierto el corazón de la manzana, el zapatista toma con mucho cuidado las semillas, va y ara un pedazo de tierra y las siembra.

Después, el zapatista riega la matita con sus lágrimas y sangre, y vela el crecimiento. El zapatista no verá el manzano florecer siquiera, ni mucho menos los frutos que dará. Dice Durito que el zapatista sembró el manzano para que un día, cuando él no esté, alguien cualquiera pueda cortar una manzana madura y ser libre para decidir si se la come en un arreglo frutal, en puré, en jugo, en un pastel o en uno de esos odiosos (para Durito) refrescos de manzana.

Dice Durito que el problema de los zapatistas es ése, sembrar las semillas y velar su crecimiento. Dice Durito que el problema de los demás seres humanos es luchar para ser libres de elegir cómo se comen la manzana que vendrá.

Dice Durito que ahí está la diferencia entre los zapatistas y el resto de los seres humanos: 
Donde todos ven una manzana, el zapatista ve una semilla, va y prepara la tierra, siembra la semilla, la cuida. (SUBCOMANDANTE INSURGENTE MARCOS, 2002, [s. p.]).

Este bello cuento, con el que camina también la enseñanza zapatista, nos enseñó en un primer momento que si la vida es como una manzana, bien tenemos el derecho de elegir cómo comerla, pero la lucha zapatista tiene aquí un punto de encuentro importante con el trabajo en las aulas, pues más que difundir ese derecho podemos enseñar aprendiendo que hay más posibilidades, qué tal que antes de elegir cómo comerla sembramos las semillas para que alguien más goce ese derecho-posibilidad de elegir sobre su vida.

Como lo señala Fernanda Navarro: ${ }^{22}$

En suma, el gran aporte del movimiento zapatista en estos tiempos de desolación, perplejidad y violencia globalizada es habernos abierto la Posibilidad, la posibilidad que si bien no afirma ni niega, promete un nuevo despertar de esperanza de vivir otro mañana. Es pues, a esta Posibilidad a lo que debemos nuestra lealtad eterna.

Entonces, para hacer grieta en los muros del aula, hemos aprendido de las compañeras y compañeros zapatistas:

- Que el dolor es capaz de convertirse en rabia, para ser después rebeldía y con ello esperanza del mañana.

- Que el sistema también somos nosotros, cuando entre mujeres nos agredimos, cuando el machismo se manifiesta, cuando seguimos estereotipos 0 cuando ignoramos el dolor social, muertes, despojo, injusticias, devastación de la naturaleza.

- A cuestionarnos: ¿y tú qué? Pues las cuentas, los porqués o explicaciones de lo que somos, hacemos y vamos a hacer es algo que se rinde frente al espejo.

- Que ser mejor no necesariamente es dejar de ser lo que eres, sino respetarse y responsabilizarse pensando la práctica para transformarla y transformarse así mismo(a), aprendiendo a establecer lazos colectivos, dar sentido a nuestras vidas.

- Que cuidar a la madre tierra es cuidarnos, porque como bien señalan las y los zapatistas, "cuando la tierra duele, duele todo".

- Que todo lo que vale la pena se construye en colectivo, compartiendo se aprende y se construye.

- Que para leer el mundo y transformarlo transformándonos es necesario desarrollar un pensamiento crítico.

- Que la lucha es social y que entonces la resistencia se organiza organizándonos, cada quien su tarea, desde su geografía, su fecha, su espacio, su posibilidad. 
23 Conforme Que retiemble en sus centros la tierra, desde el CIDECI-UNITIERRA, Chiapas, octubre de 2016. Declaración final del Quinto Congreso Nacional Indígena celbrado entre el 11 y 14 de octubre de 2016.
Gracias icompañeras y compañeros de espíritu rebelde! por permitirnos compartir nuestro caminar agrietando el muro del aula, buscando nacer una casamundo cada vez más multicolor, en donde quepan muchos mundos. Donde las rabias que somos marcan los amores que nos desvelan e impulsan nuestro erotismo que nace en sueños y nos prepara cada vez mejor para hermanarnos con la solidaridad que se viene tejiendo en colectivo y que como el zapatismo, algún día será más que una utopía, pues será una realidad.

\section{P.D: "QUE RETIEMBLE EN SUS CENTROS LA TIERRA"}

La creatividad zapatista y su coherencia en el Mandar Obedeciendo pronto sorprenderá de nuevo al mundo, ahora con su declaración final del Congreso Nacional Indígena, organizado con el EZLN:23

Es así que nos reunimos a celebrar la vida en el Quinto Congreso Nacional Indígena que tuvo lugar del 9 al 14 de octubre de 2016 en el CIDECI-UNITIERRA, Chiapas, desde donde nuevamente nos damos cuenta de la agudización del despojo y la represión que no han parado en 524 años en que los poderosos iniciaron una guerra que tiene como fin exterminar a los que de la tierra somos y que como sus hijos no hemos permitido su destrucción y muerte para beneficiar a la ambición capitalista que no conoce fin, más que la destrucción misma. La resistencia por seguir construyendo la vida hoy se hace palabra, aprendizaje y acuerdos.

[...]

Ante todo lo anterior nos declaramos en asamblea permanente y consultaremos en cada una de nuestras geografías, territorios y rumbos el acuerdo de este Quinto CNI para nombrar un concejo indígena de gobierno cuya palabra sea materializada por una mujer indígena, delegada del CNI como candidata independiente que contienda a nombre del Congreso Nacional Indígena y el Ejército Zapatista de Liberación Nacional en el proceso electoral del año 2018 para la presidencia de este país. (ENLACE ZAPATISTA, 2016b, [s. p.]).

\section{REFERENCIAS}

CONFERENCIA de prensa Sub Galeano a medios libres. 12 ago. 2014. 1 post (78 min). Disponible en: <https://www.youtube.com/watch?v=tSVH87oUMb4>. Acceso en: 10 abr. 2017.

EL PENSAMIENTO crítico frente a la hidra capitalista $\mathbf{0 3 7}^{\mathbf{2 4}}$. 25 mayo 2015a. 1 post (55 min 
44 s). Disponible en: <https://www.youtube.com/ watch?v=LazwMMff63c $>$. Acceso en: 10 abr. 2017.

EL PENSAMIENTO crìtico frente a la hidra capitalista $069^{25}$. 5 jun. 2015b. 1 post (86 min 15 s). Disponible en: <https://www.youtube.com/ watch?v=DMdhypnfHMk> . Acceso en: 12 abr. 2017.

EZLN. En: El pensamiento crítico frente a la Hidra Capitalista I. Participación de la Comisión Sexta del EZLN. [s. l.]: [s. n.], [s. d.].

ENLACE ZAPATISTA. Cuáles son las características fundamentales de la IV Guerra Mundial?. 1 feb. 2003a. Disponible en: <http://enlacezapatista.ezln. org. $\mathrm{mx} / 2003 / 02 / 01 / c u a l e s-s o n-l a s-c a r a c t e r i s t i c a s-$ fundamentales-de-la-iv-guerra-mundial $>$. Acceso en: 10 abr. 2017.

ENLACE ZAPATISTA. Palabras por el nacimiento de las Juntas de Buen Gobierno. 9 ago. 2003b. Disponible en: <http://enlacezapatista.ezln.org.mx/2003/08/o9/ subcomandante-marcos-palabras-por-el-nacimiento-delas-juntas-de-buen-gobierno>. Acceso en: $10 \mathrm{abr} .2017$.

ENLACE ZAPATISTA. Comandanta Miriam. 6 de mayo 2015a. Disponible en: <http://enlacezapatista.ezln. org.mx/2015/05/o6/comandanta-miriam-6-de-mayo $>$. Acceso en: 10 abr. 2017.

ENLACE ZAPATISTA. Compañera escucha Selena. 6 mayo 2015b. Disponible en: <http://enlacezapatista.ezln. org.mx/2015/o5/o6/companera-escucha-selena-6-demayo >. Acceso en: 10 abr. 2017.

ENLACE ZAPATISTA. Una casa, otros mundos. México, julio/ago./sept. 2016a. Disponible en: <http:// enlacezapatista.ezln.org.mx/2016/o9/12/una-casa-otrosmundos>. Acceso en: 10 abr. 2017.

ENLACE ZAPATISTA. Que retiemble en sus centros la tierra. Chiapas, octubre de 2016b. Disponible en: <http:// enlacezapatista.ezln.org.mx/2016/10/14/que-retiembleen-sus-centros-la-tierra/> . Acceso en: 10 abr. 2017.

LOS PUEBLOS Zapatistas y la Otra Educación I. 11 dez. 2011. 1 post (21 min 2s). Disponible en: <https:// www.youtube.com/watch?v=FfQkwxODO44>. Acceso en: 10 abr. 2017.

NAVARRO, Fernanda. El Otro Prólogo. In: Relatos del viejo Antonio. Textos del Subcomandante Insurgente Marcos. México: Ediciones Rebeldía, 2011. p.14.

SUBCOMANDANTE INSURGENTE MARCOS. Los zapatistasylas manzanas. 2002. Disponibleen: $<$ http:// 
26 SubMoisés - El pensamiento crítico frente a la hidra capitalista.

27 SubGaleano - La construcción del pensamiento crítico. palabra.ezln.org.mx/comunicados/2002/2002_11.htm>. Acceso en: 10 abr. 2017.

SUBCOMANDANTE INSURGENTE MOISÉS. Resistencia y Rebeldía I. San Cristóbal, 6 mayo 2015. Grieta medio para armar. Disponible en: <http://www.grieta.org. $\mathrm{mx} /$ index.php/2015/05/06/resistencia-y-rebeldia-isubcomandante-insurgente-moises $>$. Acceso en: $10 \mathrm{abr}$. 2017.

WIKIPEDIA. Tratado de Libre Comercio de América del Norte. [s. d.]. Disponible en: <https:// es.wikipedia.org/wiki/Tratado_de_Libre_Comercio_de_ Am\%C3\%A9rica_del_Norte>.Acceso en: 10 abr. 2017.

Recebido em: 00/00/2017

Aprovado em: 00/00/2017

\section{ANEXO \\ ¿Cómo estudiar escuchando y viendo la REBE- LIÓN ZAPATISTA?}

CONFERENCIA de prensa del EZLN con los Medios Libres. 15 ago. 2014.1 post (64 min $11 \mathrm{~s}$ ). Disponible en: $<$ https://www.youtube.com/watch?v=8AU5ZtSpw-k>. Acceso en: 10 abr. 2017.

CRÓNICA zapatista preparada para el X Seminario Freiriano Internacional. 8 mayo 2016. 1 post (13 min 47 s). Disponible "en": <https://www.youtube.com/ watch?v=U1psszDUR3I>. Acceso en: 10 abr. 2017.

ENTRE LA LUZ y la sombra (completo). 24 mayo 2014. 1 post (58 min $10 \mathrm{~s}$ ). Disponible en: <https://www. youtube.com/watch?v=ZuV4eS2S4RI $>$. Acceso en: 10 abr. 2017.

EL PENSAMIENTO crítico frente a la hidra capitalista $\mathbf{0 3 7}^{\mathbf{2 6}}$. 25 mayo 2015. 1 post (55 min 44 s). Disponible en: <https://www.youtube.com/ watch?v=LazwMMff63c $>$. Acceso en: 10 abr. 2017.

EL PENSAMIENTO crìtico frente a la hidra capitalista 069 $^{27}$. 5 jun. 2015. 1 post (86 min 15 s). Disponible en: <https://www.youtube.com/ watch?v=DMdhypnfHMk>. Acceso en: 12 abr. 2017. 
EZLN: Nuestra lucha como mujeres. Comandanta Miriam. 26 jun. 2015. 1 post (22 min 32 s). Disponible en: $<$ https://www.youtube.com/watch? $\mathrm{v}=$ sFwn77aUTyU $>$. Acceso en: 12 abr. 2017.

LOS PUEBLOS zapatistas y la Otra Educación I. 11 dez. 2011. 1 post (21 min 2 s). Disponible en: <https:// www.youtube.com/watch?v=FfQkwxODO44>. Acceso en: 10 abr. 2017.

SUBCOMANDANTE Insurgente Galeano - La visión de los vencidos. 9 mayo 2015. 1 post (23 min 15 s). Disponible en: <https://www.youtube.com/ watch?v=WfQA8AM9m-U>. Acceso en: 10 abr. 2017

SUBCOMANDANTE Insurgente Galeano - Del Gato-Perro: El navío y la Otroas. 2015. 1 post (17 min 8 s). Disponible en: <https://www.youtube.com/ watch?v=APiZXDpVOGg $>$. Acceso en: 10 abr. 2017.

SUBCOMANDANTE Marcos - De la política, sus finales y sus principios. 2 dez. 2012a. 1 post (22 min 14 s). Disponible en: <https://www.youtube.com/ watch?v=afVBK7ehhKY>. Acceso en: 10 abr. 2017.

SUBCOMANDANTE Marcos - Historia de libros inhumanos. 19 dez. 2012b. 1 post (13 min $40 \mathrm{~s}$ ). Disponible en: <https://www.youtube.com/watch?v=tE56CFYXf7U $>$. Acceso en: 10 abr. 2017.

SUBCOMANDANTE Marcos - Ni el centro ni la periferia parte I. $26 \mathrm{dez}$. 2012c. 1 post $(34 \mathrm{~min}$ 53 s). Disponible en: <https://www.youtube.com/ watch?v=EgCaGqMmJYU>. Acceso en: 10 abr. 2017.

SUBCOMANDANTE Marcos - Ni el centro ni la periferia parte II. 26 dez. 2012d. 1 post $(9 \mathrm{~min}$ 30 s). Disponible en: <https://www.youtube.com/ watch?v=9757DVEGWDo>. Acceso en: 10 abr. 2017.

SUBCOMANDANTE Marcos - Ni el centro ni la periferia parte III. $26 \mathrm{dez}$. 2012e. 1 post (26 min 8 s). Disponible en: <https://www.youtube.com/ watch?v=1tStyZaIkNo $>$. Acceso en: 10 abr. 2017.

SUBCOMANDANTE Marcos - Ni el centro ni la periferia parte IV. 26 dez. 2012f. 1 post (30 min 35 s). Disponible en: <https://www.youtube.com/ watch?v=hN82JO5k_Cw $>$. Acceso en: 10 abr. 2017.

SUBCOMANDANTE Marcos - Ni el centro ni la periferia parte V. 26 dez. 2012g. 1 post (25 min). Disponible en: <https://www.youtube.com/ watch?v=cPOac1SE8xg $>$. Acceso en: 10 abr. 2017. 
SUBCOMANDANTE Marcos - Ni elcentro ni la periferia parte VI. $27 \mathrm{dez} .2012 \mathrm{~h} .1$ post $(7 \mathrm{~min}$ 59 s). Disponible en: <https://www.youtube.com/ watch?v=5JsWCvPSVKQ $>$. Acceso en: 11 abr. 2017.

SUBCOMANDANTE Marcos - Ni elcentro ni la periferia parte VII. 27 dez. 2012i. 1 post $(23 \mathrm{~min}$ 23 s). Disponible en: <https://www.youtube.com/ watch?v=zKFfCiqH_fo $>$. Acceso en: $10 \mathrm{abr} .2017$.

SUBGALANO. La niña, el muro y la grieta. 14 mayo 2015. 1 post (26 min 23 s). Disponible en: <https://www. youtube.com/watch?v=uptygYuBUiI $>$. Acceso en: $10 \mathrm{abr}$. 2017.

21 DICIEMBRE 2012 - Chiapas, México ${ }^{28} .21$ dic. 2012. 1 post (4 min 3 s). Disponible en: <https://www. youtube.com/watch?v=XNH_8nJZUKo $>$. Acceso en: 10 abr. 2017.

Recebido em: 25/02/2017 Aprovado em: 30/05/2017 